\title{
ACCEPTANCE AND REVERIFICATION OF CMM IN INDUSTRIAL CONDITIONS
}

\author{
Robert Koteras ${ }^{1}$, Michał Wieczorowski ${ }^{1}$, Piotr Znaniecki ${ }^{1}$ \\ 1 Poznań University of Technology, Division of Metrology and Measurement Systems, Institute of Mechanical \\ Technology, Piotrowo 3,60-965; e-mail: robert.koteras@gmail.com, michal.wieczorowski@put.poznan.pl, \\ piotrznaniecki@o2.pl
}

Received: 2017.12.03

Accepted: 2018.02.01

Published: 2018.03.01

\begin{abstract}
Nowadays, coordinate measuring machines (CMM) are featured by a great degree of complexity and high accuracy of manufacturing. During use of a machine, usually after periodical maintenance it is highly recommended to perform a verification test according to the same procedures as a standard verification test, including a difference that performance conformity is checked with user's declaration. Periodical verification should be performed as often as it comes from a user's experience and after every interference influencing mechanical and electronic systems of a CMM that could potentially cause a change in its accuracy parameters. The best solution is employing for that purpose an independent accredited laboratory that is featured by high competence and experience. In the paper rules of acceptance and periodical verifications are described, sources of measurement errors resulting from CMM imperfections are presented as well as examples of results for specific measurement devices installed in industry were shown.
\end{abstract}

Keywords: Coordinate Measuring Machine, calibration, reverification, current inspection

\section{INTRODUCTION}

Coordinate measuring machines are high accuracy devices, what is accompanied by a high degree of complexity and necessity to maintain high manufacturing quality. As a result of that buying and maintenance prices of CMM are always significant [11]. To protect both: a customer from purchasing a machine that does not comply with declared parameters and a manufacturer from not justified claims, a verification test of a CMM is performed. They allow to check a CMM conformity with a manufacturers declaration. While using a machine, most often after a periodical maintenance it is recommended to perform a verification test according to the same procedures as final acceptance, including a difference, that performance conformity is checked with user's declaration $[7,8]$. Periodical verification should be realized as often as it comes from a user's experience and after every interference influencing on mechanical and electronic systems of a CMM that could potentially cause a change in its accuracy parameters. An attention to competence of service performing periodical and final verification test should be paid. The aim of supervision on measurement instruments (including a CMM) is to ensure a hierarchy of standards and reference to national and international etalons. For this purpose the preformed procedures must fully comply with requirements of respective standards. In case of CMMs ISO 10360 is the one that describes particular actions and it is compatible with Guide to the Expression of Uncertainty in Measurement (GUM). 


\section{SOURCES OF ERRORS RESULTING FROM CMM IMPERFECTION}

A result of measurement realized on a coordinate measuring machine is dependent on a proper work of many components, starting from mechanical elements through electronic systems and ending on a software. It is not possible to obtain a measurement result without an error. The partial errors can be divided into the following categories $[9,14]$ :

- errors resulting from three axes system of guideways

- perpendicularity between axes $(x w y, x w z$, $y w z)$

- straightness (for $Y$ axis: $y t x, y t z$; similarly for the remaining ones)

- pitch and yaw (for $Y$ axis: $y r y, y r x, y r z$; similarly for the remaining ones)

- errors of incremental systems measuring displacement of a ram ( $x p x, y p y, z p z)$

- control errors: interpolation and discretization

- errors of computing algorithms

- errors of measuring probe system (deflection, accuracy of angle positions, form)

- errors caused by external conditions (temperature changes and gradients, vibrations)
Graphical representation of a CMM geometrical errors was shown on figure 1 .

Maximum permissible error of CMM indication during a dimension measurement $M P E_{E L}$

Indication error of a CMM during dimension measurement $E$ is an error, that can be determined by measurement of a calibrated length using this machine [8]. A parameter showing with number a CMM quality is its maximum value of indication error during measurement of a standard in reference to maximum permissible error given in a specification. Maximum permissible error of CMM indication during a dimension measurement $E_{L M P E}$ is expressed in one of the three forms:

- $E_{L, M P E}= \pm$ minimum from $(\mathrm{A}+L / \mathrm{K})$ and $B$, or

- $E_{L, M P E}= \pm(\mathrm{A}+L / \mathrm{K})$, or

$-E_{L, M P E}= \pm B$

where: $A$ is a positive constant given by a manufacturer, in micrometers;

$K$ is a positive constant given by a manufacturer, no unit;

$L$ is a measured length, in millimeters;

$B$ is a maximum permissible error $\mathrm{E}_{\mathrm{L}, \mathrm{MPE}}$ in micrometers, determined by a manufacturer $[4,8]$.

Constant A depends on accuracy of a measuring probe, measurement system, type of measure-

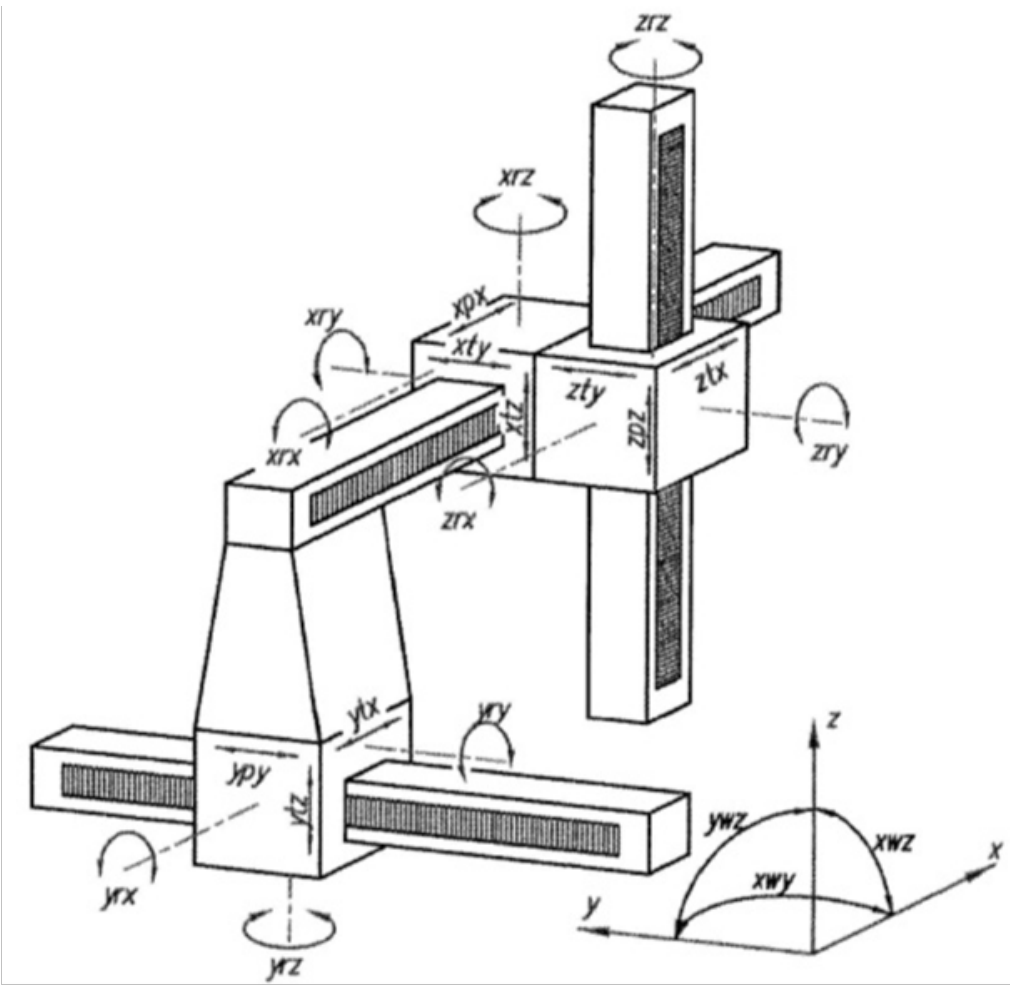

Fig. 1. A geometrical scheme of CMM errors [10] 
ment and reference system of a CMM coming from short wave linear and rotational errors. Constant $\mathrm{K}$ depends on long wave errors of standard and deformation of a CMM reference system (long wave linear and rotational errors) [8].

In the case of periodical verification tests maximum permissible error may be defined by a user. This situation usually takes place when a CMM was used for many years and is worn out, but quality of measurements can be still acceptable, although it is worse than originally declared by a manufacturer.

\section{REALIZATION OF A FINAL AND PERIODICAL VERIFICATION TEST}

The idea of dimension measurement procedure described in ISO 10360-2 enables for an assessment of a coordinate measuring machine performance, i.e. to verify whether it is possible to realize measurements with accuracy parameters

a)

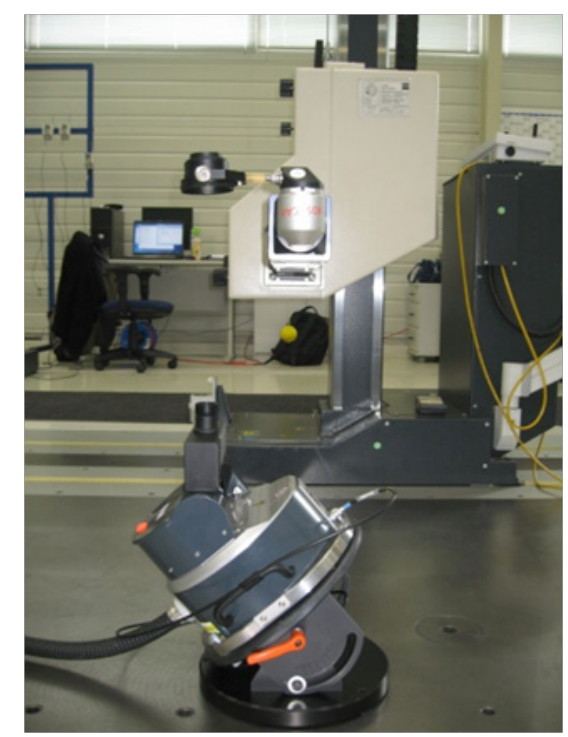

c)

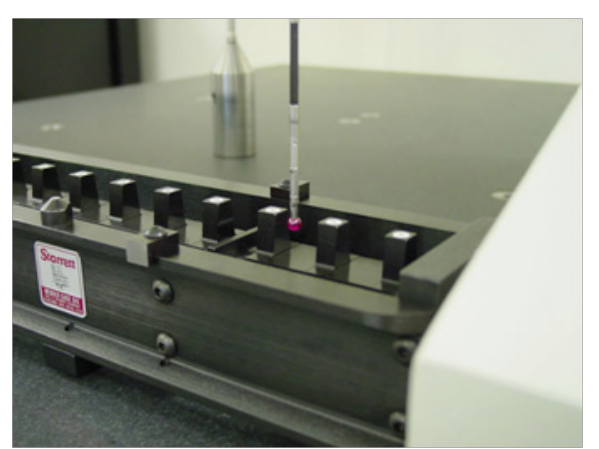

better than maximum permissible error $E_{L, M P E}$. Furthermore, repeatability of length measurement is checked. Length measurement standards are used for this, where the greatest length of a standard must reach at least $66 \%$ of three dimensional diagonal in a volume of the CMM. The following standards can be used (fig. 2):

- set of gauge blocks,

- length step standard,

- other standards enabling a volumetric verification, e.g. a ball-bar type,

- laser interferometer.

A particularly useful option while checking a CMM with large measurement volume in this procedure is using a laser interferometer. Measurements of five standards located in seven different positions are realized three times, and 105 measurement results obtained this way are presented as $E_{0}$ errors super positioned on a plot with $E_{0, M P E}$ (fig. 3).

An ISO standard defines how the length standards should be located in the volume of a CMM

b)

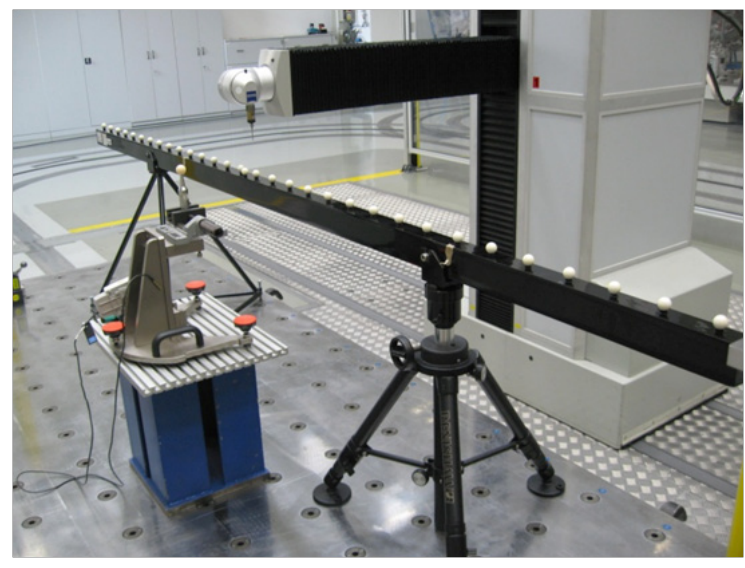

d)

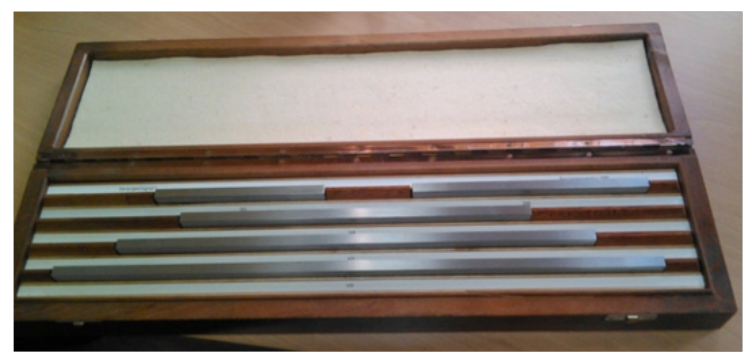

Fig. 2. a) Etalon Laser Tracer, b) ball-bar, c) step standard [12], d) set of gauge blocks 


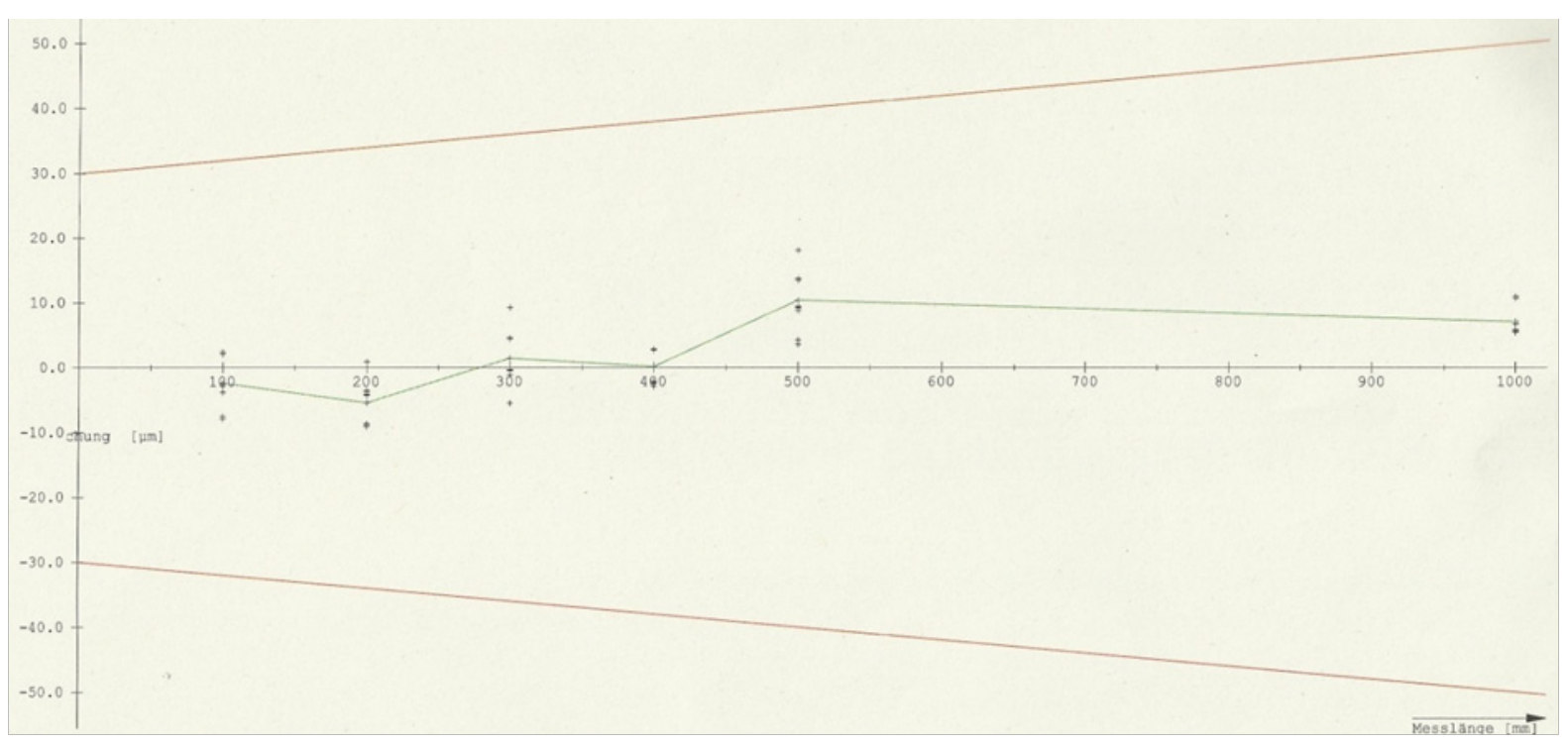

Fig. 3. Example of plot with $E_{0}$ errors together with $E_{0, \mathrm{MPE}}$

and these positions are collected together in a specific table (table 1 is an example).

Graphic interpretation of this was presented on figure 4.

Then, three times a measurement of five length standards in two locations is performed, with a measurement stylus of which a distance from a center of ram axis to the stylus end reaches $L=$ $150 \mathrm{~mm}$ (fig. 5). It is also possible to realize this measurement task in one location, with a measurement stylus in two different positions (fig. 6).

This makes it possible to assess a ram error depending on a distance from a center of ram axis to the stylus end. The differences obtained that way between a true value and reported one $E_{150}$ are plotted together with $E_{150, M P E}$ (fig. 7).

As it was already mentioned before all the measurements of material standards are repeated three times. Thanks to this it is possible to calculate repeatability of length measurement $R_{0}$, that should not exceed a permissible value of mea- surement repeatability $R_{0, M P L}$. Thermal expansion coefficient should be between $8 \times 10^{-6}\left[1 /{ }^{\circ} \mathrm{C}\right]$ and $13 \times 10^{-6}\left[1 /{ }^{\circ} \mathrm{C}\right]$. A CMM is considered to fulfill requirements if the parameters given before are maintained including measurement uncertainty according to ISO 14253-1 and ISO/TS 23165 $[4,8,9]$. Calibration on a ball-bar type standard was shown in figure 8 .

\section{INSPECTION OF TACTILE PROBES}

In ISO 10360-5 standard a method to inspect contact probe of CMM was described by means of a spherical standard, but a different one than that which is daily used to qualify styli and is usually an accessory to a machine. The standard suggests that a diameter should not be smaller than $10 \mathrm{~mm}$ and bigger than $50 \mathrm{~mm}$. Because one ought to expect different results for different lengths of measurement styli it is recommended to use lengths

Table 1. Location of material standards in measurement volume of a CMM [4]

\begin{tabular}{|c|l|c|}
\hline $\begin{array}{c}\text { Position } \\
\text { number }\end{array}$ & \multicolumn{1}{|c|}{ Location in a measurement volume } & $\begin{array}{c}\text { Required or } \\
\text { recommended }\end{array}$ \\
\hline 1 & Along a diagonal from point $(1,0,0)$ to point $(0,1,1)$ & required \\
\hline 2 & Along a diagonal from point $(1,1,0)$ to point $(0,0,1)$ & required \\
\hline 3 & Along a diagonal from point $(0,1,0)$ to point $(1,0,1)$ & required \\
\hline 4 & Along a diagonal from point $(0,0,0)$ to point $(1,1,1)$ & required \\
\hline 5 & Parallel to machine axis from point $(0,1 / 2,1 / 2)$ to point $(1,1 / 2,1 / 2)$ & recommended \\
\hline 6 & Parallel to machine axis from point $(0,1 / 2,1 / 2)$ to point $(1,1 / 2,1 / 2)$ & recommended \\
\hline 7 & Parallel to machine axis from point $(0,1 / 2,1 / 2)$ to point $(1,1 / 2,1 / 2)$ & recommended \\
\hline
\end{tabular}

Note: for recommendations in this table opposite corners of measurement volume were designated $(0,0,0)$ and $(1,1,1)$ in $(\mathrm{X}, \mathrm{Y}, \mathrm{Z})$ coordinates 


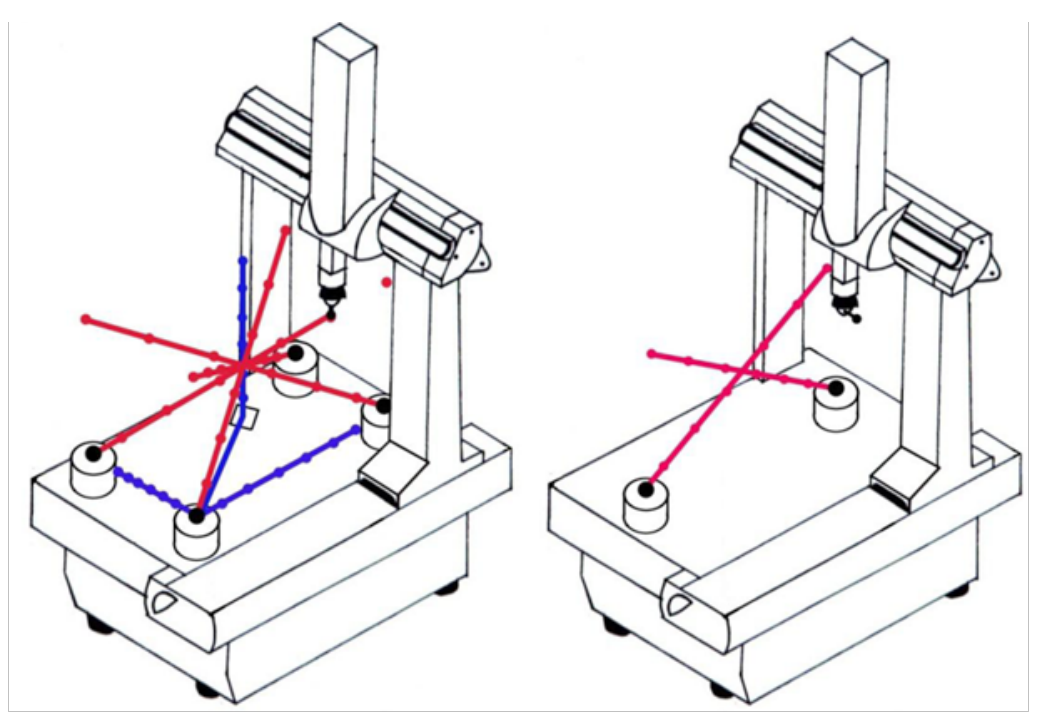

Fig. 4. Positions of a laser tracer and measurement lines while determining: on the left $-E_{0}$ error; on the right $-E_{150}$ error $[3,9]$

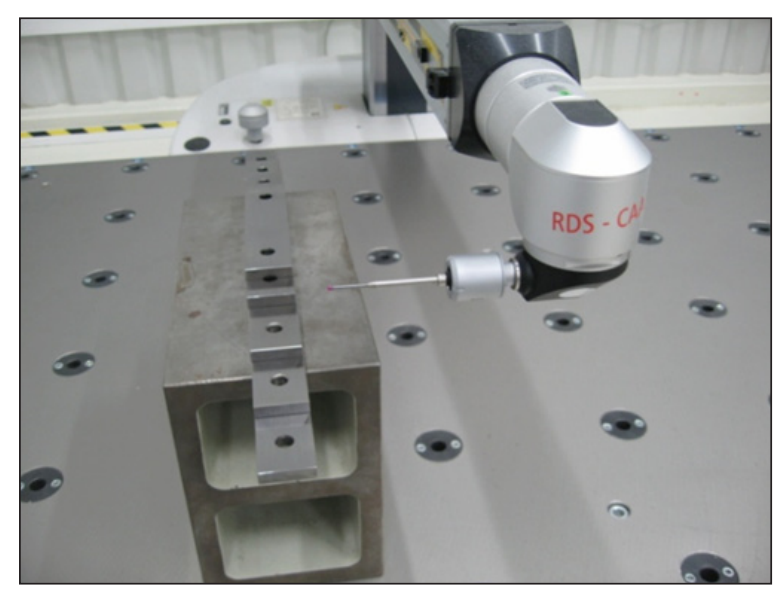

Fig. 5. A measurement probe in a position, where a distance from a center of ram axis to the stylus end reaches $L=150 \mathrm{~mm}$

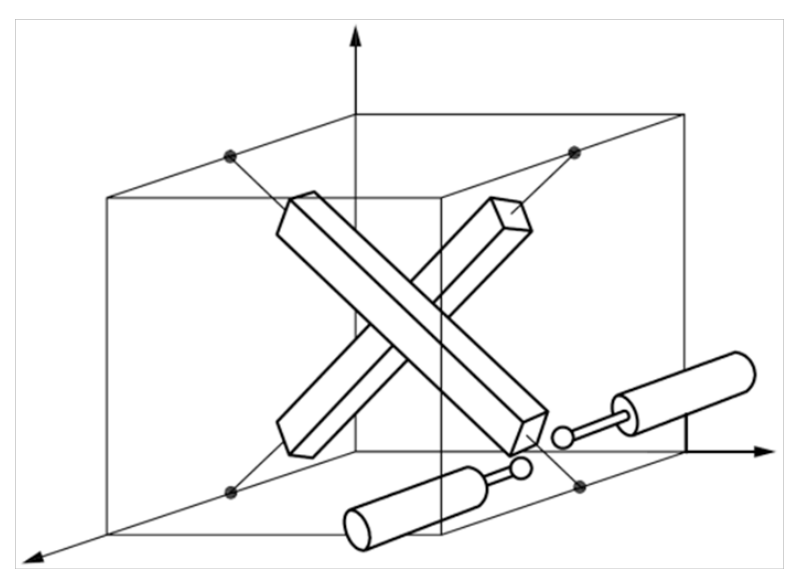

Fig. 6. An example of probe stylus orientation while determining $E_{150}$ error [4]

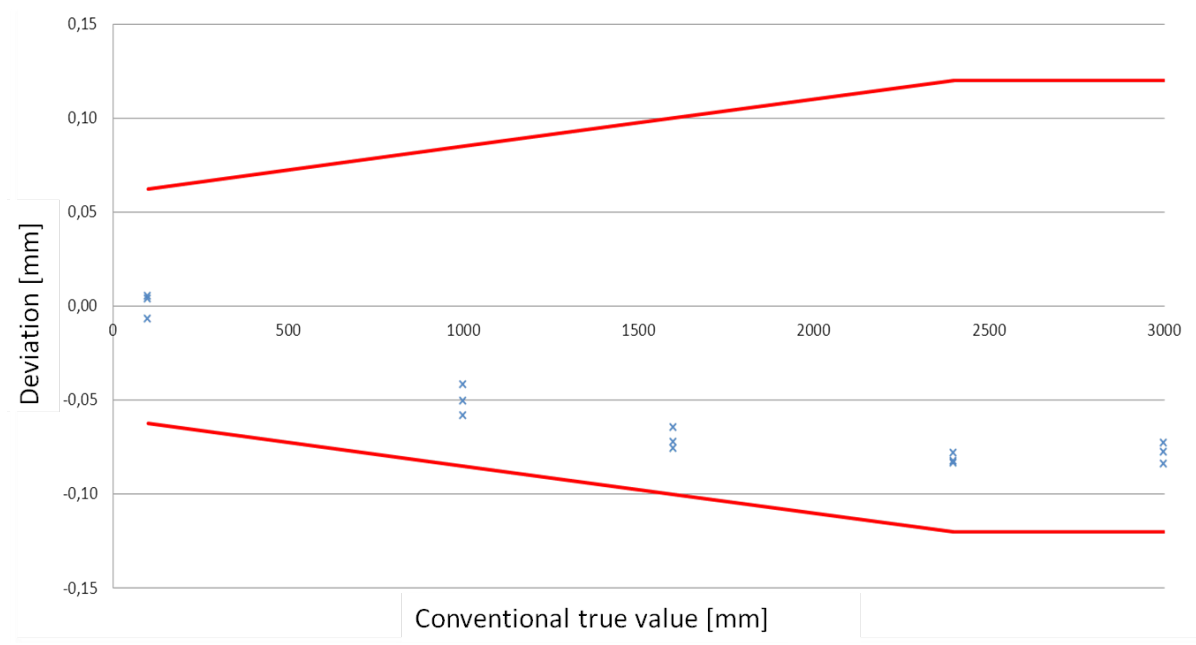

Fig. 7. An example of a plot of errors $E_{150}$ together with $E_{150, M P E}$ 


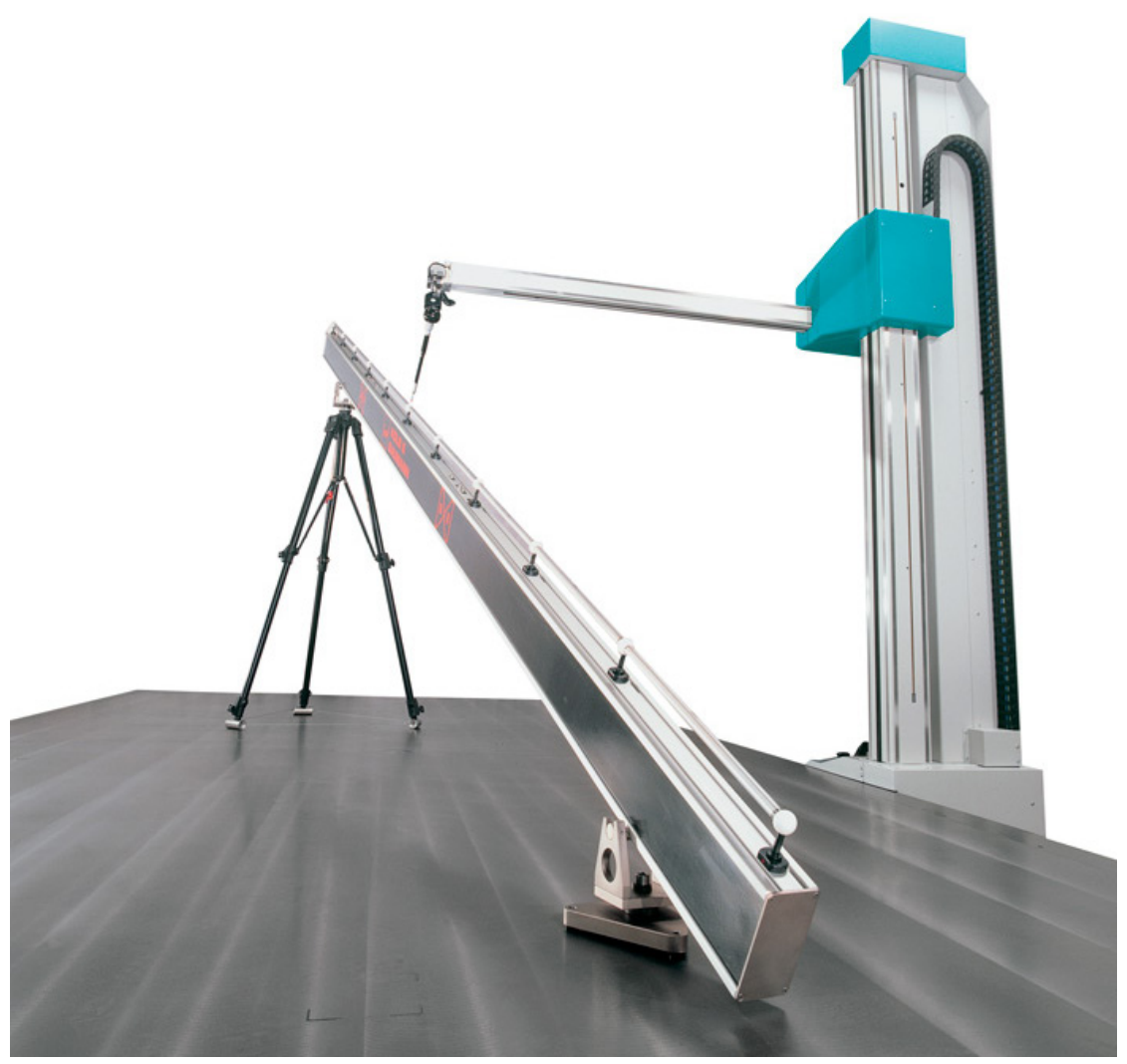

Fig. 8 . CMM calibration on a ball-bar type standard [13]

given by a probe manufacturer. Moreover, it proposes a number of lengths that can be used: 20 , $30,50,100 \mathrm{~mm}$ [5]. In figure 9 a distribution of 25 measurement points is presented.

In the case of a single probe stylus, after a measurement and calculation of reference element by means of a Gaussian method, a distance of particular points from a center of computed sphere is evaluated. A difference between the largest and the smallest distance $P_{F T U}$ together with its uncertainty (calculated according to ISO 14253-1) should not exceed a maximum permissible error of a tactile system $P_{F T U, M P E}$ (fig. 10).

When systems with a configuration of probe styli or an articulating head is concerned (fig. 11) a measurement of a standard sphere is conducted respectively with five styli (a total number of probe styli) or using five different positions of a probe. From five spheres calculated this way, a parameter corresponding to a location error is computed, as the biggest range of spheres centers coordinates in any axis. Depending on a probe type this parameter is designated in the following way:

- $P_{L T M}$ - a location error of a non articulating probe with multiple styli

- $P_{L T N}-$ a location error of a non articulating probe with multiple probes
- $P_{L T E}-$ a location error of an articulating probe without a map of errors of a joint

- $P_{L T I}$ - a location error of an articulating probe with a map of errors of a joint

From all of the 125 measured points a Gauss reference sphere is created and its diameter is compared with a nominal diameter taken from a standard sphere calibration certificate. A difference between these two diameters is an error parameter of dimension representation. Possible designations of this parameter are the following:

- $P_{S T M}-$ a dimension representation error of a non articulating probe with multiple styli

- $P_{S T N}-$ a dimension representation error of a non articulating probe with multiple probes

- $P_{S T E}-$ a dimension representation error of an articulating probe without a map of errors of a joint

- $P_{S T I}$-a dimension representation error of an articulating probe with a map of errors of a joint

Also from these 125 measured points and a created Gauss reference sphere a form error is computed. Its parameter has the following designations:

- $P_{F T M}-$ a form representation error of a non articulating probe with multiple styli 
a)

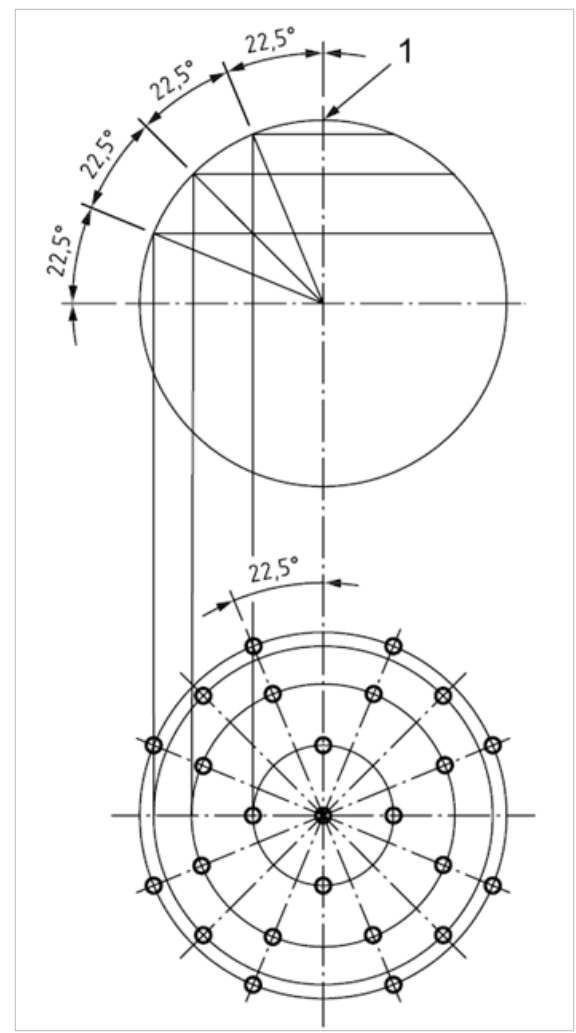

b)

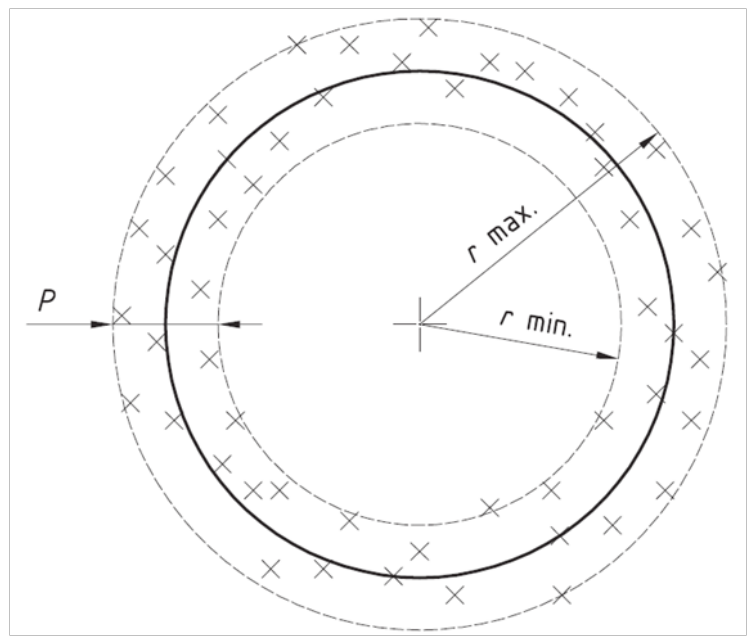

Fig. 9. On the left: distribution of measurement points on spherical standard, on the right: a method of measurement probe error calculation $P[5]$

- $P_{F T N}-$ a form representation error of a non articulating probe with multiple probes

- $P_{F T E}-$ a form representation error of an articulating probe without a map of errors of a joint

- $P_{F T I}-$ a form representation error of an articulating probe with a map of errors of a joint

Compliance with requirements is confirmed when respective values of maximum permissible errors are not exceeded: $P_{L T J, M P E}, P_{S T, M P E}, P_{F T j, M P E}$ (where instead of $\mathrm{j}$ designations: $M, N, E$ or $I$ are given) together with measurement uncertainties calculated for them according to ISO 14253-1 and ISO/TS 23165. When an articulated probe is considered it is necessary to use certain probe extensions for inspection. It is recommended to use: 50, 100, 200, $400 \mathrm{~mm}$. If a manufacturer did not specify in a different way a measurement stylus of $20 \mathrm{~mm}$ is used. The choice of positions of the articulated probe should correspond to styli directions of a set configured into a typical star. Position of a standard sphere ought to be close to position of a ball used for styli qualification. A distance between them must not be smaller than the length of the longest used probe extension $[1,3,5,10]$.

\section{INDUSTRIAL ASPECTS OF FINAL AND PERIODICAL VERIFICATION OF A CMM}

Acceptance tests are the most often performed inspections. They are executed when a purchased machine is installed and are considered as a proof of fulfilling customer requirements and expectations by a manufacturer, as well as a customer gets a certificate that the machine can be used in a production process at his premises. This inspection is very important for both sides.

There are three crucial features of acceptance test:

1. It enables for an acceptance of a CMM

2. Its cost is included in a price - no additional fee 3. A result of it is a certificate necessary from quality assurance system point of view

However, it is important to remember that accuracy parameters of a coordinate measuring machine can change in time, because of wear as well as a result of a breakdown or collision that may happen during a daily operation. Then a reverification (periodical or interim test) should be planned to find out real errors of a device. This inspection also has a lot of benefits. For exam- 
a)

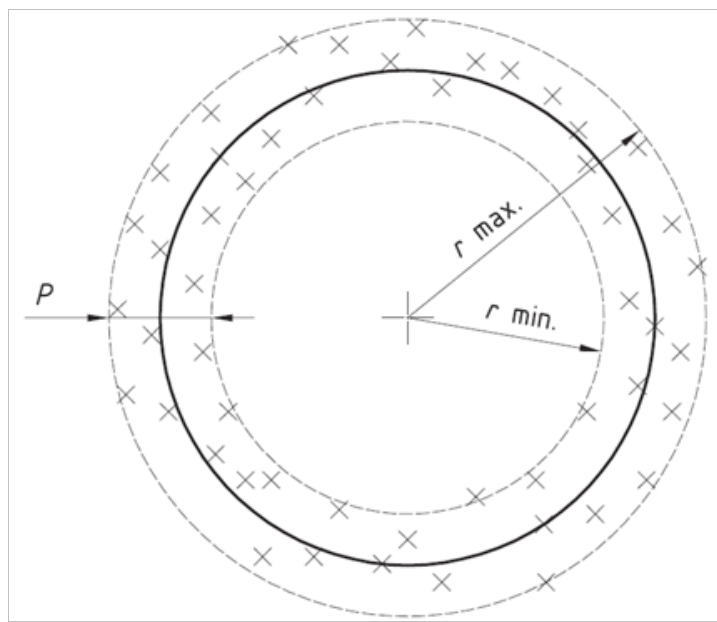

b)

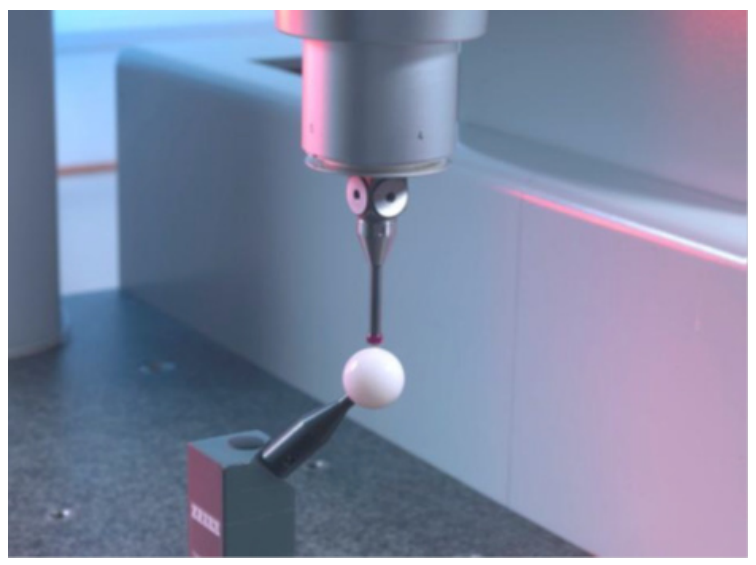

Fig. 10. A procedure of $P_{F T U}$ parameter computation $[2,8]$

a)

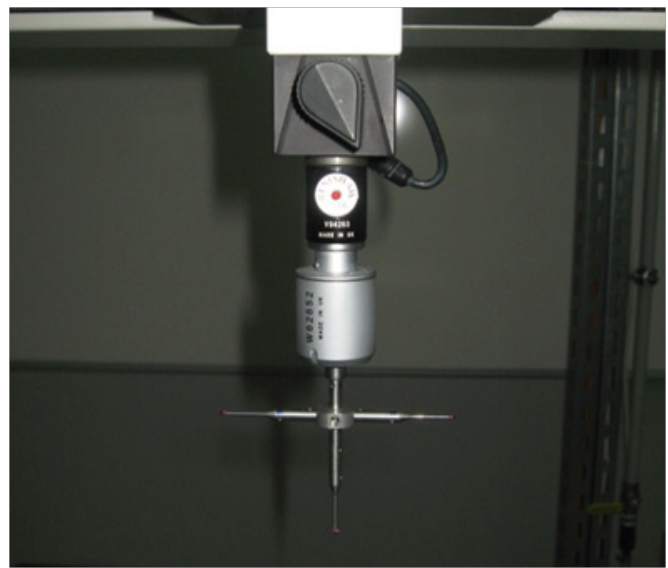

b)

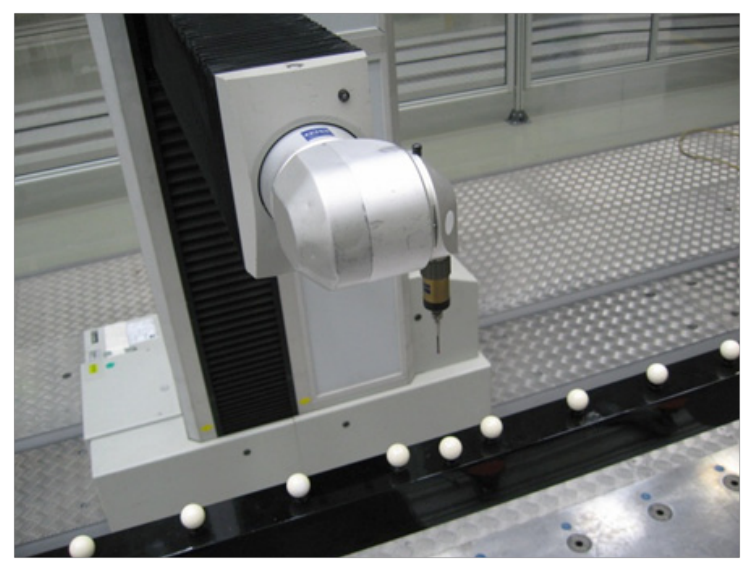

Fig. 11. On the left: a star type multi stylus configuration, on the right: an articulating probe

ple it enables for finding and fast repairing of a problem that can cause CMM inaccuracies. This makes both: a time of repairing a fault and its cost much smaller. Furthermore, it positively influences supervision over a production process, as its status is assessed basing on measurement results and also they are an input for necessary correction actions. Wrong measurement can lead to false ideas and settings which in turn can cause a factory significant costs.

An important feature is also ensuring independence of a party performing calibration. A bad practice is realization of calibration by the same personnel that do maintenance, regulations and repairs. The best solution is ordering calibrations at independent accredited bodies with undoubted competences. In industrial conditions, however, this is not a common situation. There are a few reasons for that. First, a trend to simplify tech- nical maintenance is observed. It is much easier to order service authorized by a CMM manufacturer that can perform a periodical maintenance and reverification together. When a CMM does not comply with manufacturer specification or user requirements, a servicing company can make all the corrections instantly. It is much more difficult to organize maintenance and reverification visits for different organizations. When a maintenance quality is questionable it is necessary to wait for responsible people often for a couple of days. Such a possibility discourages users from this solution despite its many merits. Reverification of CMM usually takes place in planned breaks in machine operation. These devices are used intensively (measurement time is very precious) so all the interruptions are considered as a financial loss. Extending a period of excluding a machine from its normal operation is then not a 
positive sign as it is seen from management point of view. Second, minimizing CMM servicing cost is also a tendency. A cost of periodical maintenance together with reverification is smaller than a sum of both actions ordered at different providers. Partially, it comes from a possibility of making at least a part of reverification already during CMM maintenance. The results of this inspection is an important information for servicing personnel showing how good the adjustments were made. Even when a new correction map CAA is elaborated, it is necessary to verify it by means of another material length standard. So reducing a price because of failing to execute a reverification will only partially cover a service by accredited laboratory. Third, CMM users from industry are used to their CMM suppliers. Particularly when a new machine is purchased it comes together with installation, training of operators including specified requirements and warranty period, within which a user does not have to worry about service and maintenance. Additionally, during this period all the inspections are done free of charge by a CMM supplier. A complex service is very convenient and it is very hard to give it up. As a result of that it is quite often that users do not look for alternative solutions even if the practiced ones are not fully correct.

\section{CONCLUSIONS}

The most often solution is keeping constant periods between reverifications depending on intensity of CMM operation. Usually, it is performed not more often than once a year directly after a periodical maintenance. Both actions are executed by the same people. If a CMM works on two or three shifts an additional simplified maintenance is realized together with a simplified reverification of machine performance. Results of such a verification confirm CMM capability for purpose of laboratory or enterprise quality assurance system. It is awareness as well as metrological culture of a laboratory that show whether fidelity of machine operation is supported by regular interim checks. Despite mentioning them in ISO 10360-2 standard they are not commonly practiced.

\section{REFERENCES}

1. Barini E. M., Tosello G., De Chiffre L.: Uncertainty analysis of point-by-point sampling complex surfaces using touch probe CMMs. DOE for complex surfaces verification with CMM, Precision Engineering, 34, Elsevier, 2010.

2. Flack D., Good Practice Guide No. 42. CMM Verification: National Physical Laboratory, Teddington, 2011.

3. Gąska A. Modelowanie dokładności pomiaru współrzędnościowego z wykorzystaniem metody Monte Carlo: Praca doktorska, Politechnika Krakowska, 2011. (in Polish)

4. ISO 10360-2:2009, Geometrical product specifications (GPS) - Acceptance and reverification tests for coordinate measuring machines (CMM) - Part 2: CMMs used for measuring linear dimensions.

5. ISO 10360-5, CMM using single and multiple stylus contacting probing systems, Second edition, 2010.

6. ISO 15530-3:2011, Geometrical product specifications (GPS) - Coordinate measuring machines (CMM): Technique for determining the uncertainty of measurement - Part 3: Use of calibrated workpieces or measurement standards, 2011.

7. Neumann H.J., Koordinatenmesstechnik, Expert Verlag, 1993.

8. PN/EN/ISO 10360-1, Specyfikacje geometrii wyrobów (GPS). Badania odbiorcze i okresowe współrzędnościowych maszyn pomiarowych (CMM). Część 1: Terminologia, Polski Komitet Normalizacyjny, Warszawa, 2003. (in Polish)

9. Ratajczyk E.: Współrzędnościowa technika pomiarowa. Maszyny i roboty pomiarowe, Oficyna Wydawnicza Politechniki Warszawskiej, 1994. (in Polish)

10. Sładek J.: Dokładność pomiarów współrzędnościowych, Politechnika Krakowska, Kraków, 2011. (in Polish)

11. Wieczorowski M., Sładek J., Nocuń M., Kryteria doboru współrzędnościowej maszyny pomiarowej WMP, Stal Metale \& Nowe Technologie, 1-2, 2016, 88-98. (in Polish)

12. www.core-services.com, 10-01-2017

13. www.koba.de, 13-03-2017

14. Znaniecki P.: Koncepcja systemu nadzorowania współrzędnościowych maszyn pomiarowych, Budowa i Eksploatacja Maszyn, Akademia Techniczno Humanistyczna w Bielsku Białej, 2012. (in Polish) 